\title{
La ciudad de Punta del Este entre dos cortos y dos novelas: Análisis de las representaciones urbanas desde la promoción turística, el audiovisual y la literatura
}

\author{
THE CITY OF PUNTA DEL ESTE IN TWO AUDIOVISUALS AND TWO NOVELS: AN \\ ANALYSIS OF URBAN REPRESENTATIONS IN TOURISM PROMOTION, FILM AND \\ LITERATURE
}
A CIDADE DE PUNTA DEL ESTE ENTRE DOIS AUDIOVISUALES E DOIS NOVELAS: ANÁLISE DE REPRESENTAÇÕES URBANAS A PARTIR DA PROMOÇÃO DO TURISMO, AUDIOVISUAL E LITERATURA

\author{
Victoria Lembo $* 1$ \\ victorialembo@gmail.com
}

\begin{abstract}
Resumen
Las reflexiones planteadas en el presente artículo se desprenden de una investigación de mayor alcance en la cual busco explorar las representaciones construidas en torno a la ciudad de Punta del Este a través del análisis de diversos discursos, modos de expresión, simbolización, producción de significaciones del espacio urbano provenientes de la prensa, el cine, las artes plásticas y la literatura. En este documento analizaré las representaciones construidas sobre Punta del Este -especialmente aquellas que abordan el espacio urbano, su entorno natural y las relaciones humanas tejidas en la ciudad balnearia-desde la promoción turística, del arte y la literatura. El propósito es identificar dichas representaciones y analizar qué lugar ocupan en los procesos de enunciación y significación de la ciudad.
\end{abstract}

Palabras clave: Punta del Este, ciudad, construcciones discursivas, representaciones

\footnotetext{
Abstract

The reflections raised in this article are derived from a more far-reaching investigation in which I seek to explore representations of the city of Punta del Este through an analysis of various discourses, modes of expression, symbolization, and production of meanings about the urban space in media, cinema, visual arts and

$1 *$ Centro Universitario de la Región Este. Universidad de la República

Tekoporá ${ }^{\circledR}$. Centro Universitario de la Región Este. Universidad de la República (C) Lembo. (2021)

Este es un artículo de Acceso Abierto distribuido bajo licencia Creative Commons (CC BY NC 4.0)
} 
literature. In this article, I analyze representations of Punta del Este-especially those that address how the urban space, its natural environment and human relationships are interwoven in this seaside resort city-in tourism promotional material, art and literature. My aim is to identify these representations and analyze what place they occupy in the processes of enunciation and significance of the city.

Keywords: Punta del Este, city, discursive constructions, representations

\section{Resumo}

As reflexões levantadas neste artigo são oriundas de uma investigação de maior alcance, na qual busco explorar as representações construídas em torno da cidade de Punta del Este por meio da análise de diversos discursos, modos de expressão, simbolização, produção de sentidos do urbano. espaço da imprensa, cinema, artes plásticas e literatura. Neste documento irei analisar as representações construídas sobre Punta del Este-especialmente aquelas que abordam o espaço urbano, seu ambiente natural e as relações humanas tecidas na estância balnear-a partir da promoção do turismo, da arte e da literatura. $O$ objetivo é identificar essas representações e analisar o lugar que ocupam nos processos de enunciação $e$ significação da cidade.

Palavras-chave: Punta del Este, cidade, construções discursivas, representações

\section{Introducción}

Como cualquier otra ciudad del mundo, Punta del Este es difícil de caracterizar y abordar, sobre todo si partimos de la idea de que una ciudad es mucho más que el producto de un plan urbanístico o un territorio que alberga habitantes, visitantes, edificaciones, plazas y parques, calles y avenidas. Para este análisis, en el cual propongo trabajar con las representaciones del espacio urbano provenientes de la publicidad, el arte y la literatura, partiré de la base de que una ciudad no sólo está constituida por una realidad física, territorial y sociopolítica, sino que también es una realidad imaginaria, simbólica y discursiva. En este sentido, abordaré analíticamente a la ciudad ya no como el producto de un plan urbanístico, sino como menciona Remedi (s.f.), como una entidad múltiple y problemática, constituida por una realidad física, una realidad socio-política, una realidad psicológica e imaginaria, una realidad sensual y estética, una realidad simbólico-discursiva. Esta forma de comprender el espacio urbano que ahora resulta tan evidente y necesaria - en el que se busca articular lo socio-económico y material con lo socio-simbólico y discursivo, poniendo en juego el mundo de los sólidos y el de los no sólidos (Lindón, 2007)—es relativamente reciente, y fue producto de un proceso extenso y complejo que implicó importantes giros conceptuales.

Los estudios de la ciudad realizados desde una disciplina urbana surgen a 
mediados del siglo XIX y lo hacen bajo el paradigma de la modernidad, la apuesta al racionalismo, la ciencia y la técnica. Con ellos se buscó resolver todos los problemas relacionados con el "modo de vida" y el "modo de habitar" humano de ese momento. Los espacios urbanos fueron abordados con el fin de reformar aquellos lugares que como señala Green (2008) eran más propios de tiempos bárbaros que de los sueños utópicos de la Ilustración. Para ello, el urbanismo se enfocó en lo material, dejando de lado todo aquello, como la dimensión cultural de la vida en las ciudades, por no ser considerado relevante para el abordaje analítico.

En lo que respecta a Latinoamérica, los estudios urbanos también han optado durante décadas por enfoques que priorizaron los componentes materiales, los socioeconómicos y los sociopolíticos (Lindón, 2007). Es a partir de la década del noventa en que se evidencia que ciertas dimensiones fundamentales del fenómeno urbano (básicamente los componentes socio-culturales) habían quedado relegadas de los análisis. Desde ese momento se consideró fundamental acercarse a teorías y metodologías volcadas a los estudios humanísticos para con ello construir desde una base amplia la lectura de la ciudad. Intelectuales como Ángel Rama y Beatriz Sarlo desde el campo literario; Richard Morse y José Luis Romero desde la historia; Adrián Gorelik, Anahí Ballent, Jorge Liernur y Graciela Silvestri desde la arquitectura y Jesús Martín Barbero, Néstor García Canclini, Rossana Reguillo y Armando Silva desde la comunicación, sentaron las bases para promover, desde enfoques interdisciplinarios y multidisciplinarios, la articulación de lo material con lo subjetivo y representacional. Asimismo, otorgaron un lugar destacado a conceptos analíticos como las construcciones discursivas, los imaginarios urbanos, las representaciones sociales (muchas veces provenientes del arte y la literatura) (Lindon 2007; Vera, Gravano y Aliaga, 2019).

A partir de estos giros conceptuales, la ciudad pasó a concebirse y abordarse ya no como el producto de un plan urbanístico "emocionalmente neutro," instrumentado para enfrentar al caos y establecer el orden (Rubio, 2020), sino como una realidad material socialmente producida y, además, como una construcción simbólico discursiva, producto de nuestra imaginación y del lenguaje. Esta nueva concepción de la ciudad abrió el campo analítico y habilitó la realización de un gran número de investigaciones que han procurado por sobre todo identificar y analizar relatos, asociaciones de sentidos, materializaciones, representaciones y prácticas.

El presente análisis se sitúa bajo esta nueva concepción de las ciudades. Esto quiere decir que Punta del Este no será reducida a un territorio con límites geográficos específicos caracterizado por sus edificaciones, plazas, calles, avenidas, infraestructura comunicacional y de servicios, sino que será concebida también-y fundamentalmente-como un lugar de representación (Segura, 2009). En este sentido, cabe aclarar que se tomará el concepto de representación como principal herramienta de análisis para pensar la ciudad. Las representaciones sociales se definen según Jodelet (1991) como una "forma de conocimiento, socialmente elaborado y compartido, con una orientación práctica y orientado a la construcción de una realidad común en un conjunto social" (p. 31) que "circulan en los discursos, en las palabras, en los mensajes, en los medios de comunicación, 
cristalizadas en las conductas y las disposiciones materiales o espaciales" (p. 25).

Por otro lado, estas pueden presentarse como variadas formas más o menos complejas:

Imágenes que condensan un conjunto de significados; sistemas de referencia que nos permiten interpretar lo que nos sucede, e incluso, dar un sentido inesperado; categorías que sirven para clasificar circunstancias, los fenómenos y a los individuos con quienes tenemos algo que ver: teorías que permiten establecer hechos sobre ellos. Y a menudo, cuando se les comprende dentro de la realidad concreta de nuestra vida social, las representaciones sociales son todo ello junto. (Jodelet, 1986, p. 472)

Partiendo de estos postulados teóricos, el objetivo del presente estudio consiste en analizar las representaciones construidas sobre la ciudad, su entorno natural y sus transformaciones, sobre el habitar el entorno urbano y sobre las relaciones humanas que en él se tejen. Para ello propongo trabajar con diferentes construcciones discursivas sobre Punta del Este. Una de ellas resulta de una producción audiovisual del Ministerio de Turismo del Uruguay (MINTUR) titulado "Fin de semana en Punta del Este," en el que se busca promocionar la visita y el disfrute de la ciudad. La otra proviene de otro corto audiovisual de carácter artístico, titulado "Cuando nadie nos visita," realizado por Lucía Nieto Salazar, una joven productora cinematográfica habitante de la ciudad balnearia. Por último, propongo para el análisis los relatos producidos en dos novelas cuyas tramas se contextualizan en la ciudad de Punta del Este, la ciudad Maldonado y alrededores: Los trabajos del amor de Damián González Bertolino (2015), y Mal don de Silvina Bullrich (1973).

Tanto los audiovisuales como las obras literarias seleccionadas abordan aspectos centrales para nuestro análisis, como las significaciones sobre el entorno natural, las transformaciones atravesadas por el territorio a lo largo del tiempo, la relación de los pobladores con la ciudad y los efectos producidos por los cambios de estación y la llegada de los turistas. En lo que respecta a la producción del MINTUR, considero que al ser un relato configurado desde un organismo oficial con un claro objetivo de promoción turística, propone una significación de la ciudad en torno a lo que se desea y se concibe posible como organización espacial y modalidades de vida urbana (Vera, Gravano y Aliaga, 2019). En dicha producción, las representaciones sobre el espacio urbano se construyen desde la presencia, la planificación y la intervención humana. La estructura, organización y funcionalidad de la ciudad está al servicio del turista, el cual aparece en el relato como una figura omnipresente. A su vez, la ciudad se vincula al ocio, al entretenimiento, al consumo de bienes naturales, al glamour y la exclusividad. Dichos componentes básicos que lograron la conformación de la imagen turística desde los inicios han sido sus rasgos más perdurables reforzándose año tras año desde la esfera pública y también desde la privada, principalmente por los agentes inmobiliarios, los inversionistas, los promotores turísticos y los medios de comunicación.

A diferencia de la anterior construcción discursiva, el corto audiovisual titulado "Cuando nadie nos visita" de Lucía Nieto Salazar, las representaciones 
sobre la ciudad y sus alrededores se construyen desde la ausencia humana y los efectos antropogénicos. Las imágenes privilegian una ciudad sin humanos, mucho más sensible a la agencia del mundo no humano. De esta forma el relato invita a problematizar los aspectos estructurales de la relación de las personas con su ambiente, contribuyendo a abandonar una visión antropocéntrica de la ciudad y su entorno y a explorar el papel que juegan los seres no humanos en la construcción de los escenarios. Es así que en este relato se pueden vislumbrar representaciones sobre la ciudad que en general quedan al margen en otras producciones discursivas provenientes de la promoción turística, la planificación, el ordenamiento y el desarrollo urbano, de la prensa o la publicidad.

Pienso que revelar las imágenes y representaciones que construyen, nombran, significan a la ciudad desde otro lugar, contribuye a enriquecer y enunciar las variantes de la complejidad urbana que la perspectiva reduccionista y homogenizadora de otros discursos omite. A partir del análisis y reflexión de estos "relatos alternos," se puede descubrir, como mencionan Silva y Gravano (2017), las diversas ciudades que conforman el espacio urbano y no solo las que demarcan las topografías de los planificadores y urbanizadores, la prensa o los libros de historia.

\section{Punta del Este}

Punta del Este es una ciudad peninsular situada en el extremo meridional de Uruguay, en el departamento de Maldonado. A su vez Punta del Este es concebido y representado como un territorio mucho más extenso que abarca por lo menos desde Punta Ballena a José Ignacio, excediendo la mera jurisdicción territorial del Municipio ${ }^{2}$. Por otra parte, Punta del Este se ubica en Uruguay pero forma parte de un circuito turístico y residencial de carácter internacional apto para vacacionar, realizar negocios o establecer una o más residencias en las cuales afincarse por cortas o largas temporadas:

En un verano de inicio soñado, por los días soleados y calurosos, en Punta del Este se ha visto circular desde el Príncipe de Liechtenstein, propietario de una de las fortunas más grandes del mundo, hasta el empresario italiano Giussepe Cipriani o la asidua visitante del balneario, la diva argentina, Susana Giménez (MINTUR, s.f.)

A su vez, Punta del Este y la ciudad de Maldonado albergan a muchos habitantes provenientes de otros lugares del país que han llegado con la intención de residir en el departamento o de establecerse de forma pasajera mientras

\footnotetext{
${ }^{2}$ Jurisdicción territorial del Municipio de Punta del Este: al Este: Desde la Parada 16 de Rambla Claudio Williman, Avda. Rpca. Argentina, Avda. Martiniano Chiossi, calle Mar Negro, calle Simón Bolívar, calle Salvador Allende, calle Tailandia, calle de la Virgen, Boulevard Artigas, Avda. Cachimba del Rey y Avda. Aparicio Saravia hasta la desembocadura del Arroyo Maldonado, incluyendo las manzanas № 456, 1802 y 1589 de Punta del Este. La Isla Gorriti está comprendida dentro de la jurisdicción que se le asigna al Municipio de Punta del Este. Recuperado de: http://miportal.maldonado.gub.uy/digesto/index.php/armado_capitulo/desplegar_armado_capitul o/581
} 
realizan "alguna changa" o para "hacer la temporada". Estos fenómenos poblacionales sitúan al departamento de Maldonado como uno de los tres (junto a Canelones y San José) con mayor crecimiento poblacional entre los años 2004 y 2011 (Maldonado se destaca particularmente debido a que su tasa de crecimiento duplica a la de Canelones y triplica a la de San José). A su vez, estos tres departamentos son los únicos con un porcentaje de la población nacida en otro lugar superior a la media nacional: para el año 2011, el 38 \% de la población de Maldonado no había nacido en dicho departamento (Instituto Nacional de Estadística, Censo 2011). Con respecto al total de su población, sabemos que para el año 2011 el departamento de Maldonado contaba con 164.298 habitantes y el municipio de Punta del Este con 11.128 (INE, 2011). Por otro lado, los planificadores de las políticas sociales estipulan que cada año se suman unos 5.000 nuevos habitantes entre los recién llegados y los nacidos estimando que para el año 2020 la población ascendió a 200.000 habitantes aproximadamente (Solomita, 2020).

En cuanto a su historia, el territorio fue primeramente habitado por poblaciones indígenas para luego volverse un enclave de explotación de lobos marinos. Ya en el siglo XIX existían algunos asentamientos en la zona que formaban un irregular pueblo de pescadores dedicados principalmente a la faena de lobos marinos y al traslado por mar de aceite y cueros desde la Isla de Lobos al puerto, y posteriormente en carretas hasta la ciudad de Maldonado. Francisco Aguilar fundó oficialmente el pueblo en la península en el año 1829 y le llamó Villa Ituzaingó. Aguilar ofició también, como uno de los primeros impulsores de la zona a través de la compra de tierras, el desarrollo de plantaciones de papas y tabaco, y la creación de la primera fábrica dedicada a la manufactura de baldosas hasta 1843, cuando la península pasó a manos de los hermanos Lafone, que siguieron el desarrollo empresarial dedicándose a los saladeros. En 1860 se instaló el primer faro y en 1889 el empresario Pedro Risso construyó el primer hotel, que funcionaba en los galpones al fondo de su empresa pesquera (Trochón, 2017).

A finales del siglo XIX comienza la forestación a cargo del inglés Henry Burnett y otros pioneros quienes plantaron pinos para frenar el avance de las dunas. Además de la plantación de bosques y la apertura de caminos y carreteras, invirtieron en hoteles y chalés para alojar a los primeros visitantes que provenían mayoritariamente de Buenos Aires (Varese, 2019). Hacia principios del siglo XX, específicamente en 1907, se declaró por ley a Punta del Este como pueblo. En ese entonces contaba con 492 habitantes, algo más de 100 casas, una escuela, la capitanía, la aduana y un único hotel de techo de chapa (Trochón, 2017):

En Punta del Este-como también sucedió en Piriápolis y Montevideo-arraigaron aquellas prácticas balnearias consolidadas en Europa a mediados del siglo XIX acompañadas de un modelo particular de urbanización impulsado, según lo ha destacado Alain Corbin, por las grandes familias aristocráticas, como fue el caso de Biarritz, Deauville, Cannes, San Sebastián, o algo más tarde y en Argentina, Mar del Plata. Un lugar de goce, pero asimismo de separación social. El balneario integró aquellos espacios concebidos para el ocio, y además para el ocio 
en exclusivo (Trochón, 2017, p. 12).

Como señala Trochón, los primeros veraneantes pertenecieron a las ya consolidadas clases altas rioplatenses. Eran estancieros, exitosos industriales y comerciantes, banqueros y dueños de los grandes medios de prensa, los cuales se relacionaban y reconocían mutuamente en la ciudad balnearia, exhibiendo específicas pautas de comportamiento y sociabilidad. La autora menciona que debido a su idiosincrasia, las exigencias sobre el balneario a medida que se desarrollaba fueron creciendo: luz eléctrica y agua potable, confort y pulcritud de los establecimientos (además de contar con salas de juego y baile), gastronomía de calidad, y cercanía a la playa eran algunas de las demandas de los visitantes que rechazaban la vida sencilla de los primeros tiempos, en procura de un mayor refinamiento y del trasplante de pautas de comportamiento urbano más sofisticado. El balneario fue concebido como un lugar de encuentro y ocio de familias aristocráticas que se instalaban por casi tres meses e interactuaban, se mostraban, reconocían y se dejaban reconocer a través de la presencia de sus nombres y fotografías en la prensa rioplatense:

La distinción en el alhajamiento de los hoteles-motores privilegiados del impulso puntaesteño-el cuidado en la vestimenta, el respeto a determinadas normas de comportamiento, la importación de prácticas que, como la beneficencia, eran tan afines a la "haute", el reconocimiento constante entre pares, son algunos mojones de estos derroteros; los mismos que fueron cimentando el imaginario de una clase (Trochón, 2017, p. 12).

Pero esta ciudad balnearia concebida para una elite, no duraría mucho tiempo. Las inversiones (atraídas por nuevos loteos realizados por rematadores) así como la especulación inmobiliaria, impulsaron la expansión del espacio urbano y ampliaron las posibilidades de acceso no sólo con fines turísticos sino también residenciales a segmentos sociales que ya no pertenecían a la élite de los primeros tiempos. A medida que la fisonomía del territorio cambiaba, producto de la demolición de los clásicos chalets lujosos y la construcción en altura, la presencia de la clase media en el territorio se hizo cada vez más evidente. La evolución del transporte tuvo mucha incidencia en este proceso: a partir de los años 30 los paseos a la península se vieron facilitados por la llegada del ferrocarril a la península, y en 1940 se habilitaron los vuelos que comunicaban Buenos Aires y Punta del Este durante del verano (Trochón, 2017; Da Cunha, Campodónico, Maronna, Duffau y Buere, 2012).

En la búsqueda de un perfil más internacional y como una forma de captar otro tipo de turistas, en 1951 se realizó el primer Festival Internacional de Cine de Punta del Este, un evento de renombre que se mantuvo a lo largo de los años ${ }^{3}$. En

\footnotetext{
${ }^{3}$ Como señalan Campodónico y Da Cunha (2009), el Festival de cine fue impulsado por el inversor argentino Mauricio Litman con el apoyo del gobierno central. En ese año el arribo de actores como Vittorio de Sica, Mario Moreno y el director sueco Ingmar Bergman posicionaron al evento y la ciudad como un referente del ámbito de la cultura. Esta oportunidad se prestó para mostrar al mundo parte de la cultura uruguaya con la organización de la Fiesta Gaucha, la Fiesta del Candombe y una muestra del Taller Torres García. Asimismo, se asoció al evento la transacción de grandes
} 
este contexto, hacia 1960 este balneario ya estaba consolidado como uno de los principales del Cono Sur (Campodónico y Da Cunha, 2009).

Desde esos años y hasta la actualidad, el departamento de Maldonado y específicamente la ciudad de Punta del Este continúan siendo de los destinos preferidos de los visitantes que llegan a Uruguay ${ }^{4}$. Como ya mencioné, las cifras de los últimos censos (realizados en 2004 y 2011) muestran que el departamento de Maldonado en el que se encuentra la ciudad de Punta del Este además de recibir visitantes en la época estival, viene aumentando su población permanente de forma sostenida debido al aumento de extranjeros que se afincan de manera permanente y a la fuerte corriente inmigratoria proveniente del resto del país, atraída principalmente por las oportunidades que brinda la industria turística y la construcción.

Algunas cifras actuales como el aumento en la tasa de la matrícula en los colegios privados más exclusivos denotan, además, un tipo de inmigración de familias pertenecientes a los sectores altos y medios altos con prácticas de consumo particulares, como habitar en residencias con servicios similares a hoteles cinco estrellas donde el metro cuadrado oscila entre los US\$3000 y 4000 (Diario La Nación, 2020). Los vuelos privados que constantemente llegan a la ciudad hace evidente el tránsito de personas que residen de forma temporal o permanente y viajan asiduamente por diversas cuestiones ${ }^{5}$. Esta tendencia se ha visto reforzada a partir de la instauración de la pandemia ocasionada por el Covid-19. A inicios de marzo del 2020 y declarada la emergencia sanitaria en nuestro país, algunos turistas decidieron quedarse, otros extranjeros y también uruguayos se trasladaron al este para ocupar sus casas de veraneo, y algunos otros alquilaron residencias para permanecer en aislamiento físico. Una muestra de ello es el aumento en las ventas de chacras que, según el director general de Planeamiento de la Intendencia de Maldonado, entre marzo y abril del 2020 se vendieron más que en todo el 2019 (Solomita, 2020). Asimismo, han aumentado las consultas sobre las matrículas en los colegios $^{6}$, sobre la posibilidad de instalación de diversas empresas en el departamento, sobre el traslado de la residencia fiscal por parte de argentinos, entre otras cuestiones (Diario La Nación, 2020).

En lo que respecta a la fisonomía del territorio como es de esperar, Punta del Este ha atravesado en las últimas décadas grandes modificaciones debido al rápido crecimiento edilicio de la franja costera, caracterizado por la demolición de

terrenos.

${ }^{4}$ Punta del Este fue el segundo lugar en preferencia con la llegada de 584.251 visitantes en la temporada de 2019. El gasto fue de U\$S 672.115.467; ocupando el primer lugar en lo referente al gasto de los servicios turísticos (MINTUR, 2019).

${ }^{5}$ El Aeropuerto Internacional Laguna del Sauce registra unos 3.000 aterrizajes privados al año, proviniendo el 70\% de Argentina y el 15\% de Brasil (Diario La Nación, junio 2020).

${ }^{6}$ A inicios del 2020, el International College recibió más de 90 consultas por matrículas: el 85\% de argentinos; el 15\% provenientes de destinos como Perú, México, Emiratos Árabes, Ecuador, Colombia; Isla Mauricio, Italia, España, Estados Unidos pero también de familias de Montevideo (Solomita, 2020). 
construcciones bajas de tipo chalés, la construcción de monumentales edificios y la reubicación de pequeñas localidades más empobrecidas (como es el caso del realojo de las familias que residen en el barrio Kennedy y El Placer) acentuando en muchos casos la brecha existente entre los sectores más prósperos y los más vulnerables. Dadas tales circunstancias, cabe suponer que las transformaciones a nivel territorial y poblacional han reconfigurado en las últimas décadas no sólo el ordenamiento urbano y la estructura sociodemográfica, sino también las prácticas espaciales (las formas en que los diferentes sectores poblacionales se distribuyen en el espacio, lo transitan y se relacionan entre sí), la construcción social del espacio (los lugares visitados y los eludidos, los rememorados y los olvidados, los exhibidos, los ocultados y/o relocalizados).

Por estos motivos, entre otras cuestiones, pienso que se hace necesario investigar las transformaciones del espacio urbano dando cabida a otros aspectos de la problemática territorial como la dimensión simbólico cultural de la vida en la ciudad. Para ello es necesario habilitar en el análisis, nuevos conceptos que vinculen las materializaciones, los relatos, las representaciones y las prácticas urbanas.

\section{Análisis de los relatos y las representaciones sobre Punta del Este a partir de dos cortos audiovisuales y dos obras literarias}

"El encuentro del mar, el sol y la arquitectura majestuosa. Punta del Este, el balneario más famoso de América del Sur, para vivirlo en un fin de semana" (MINTUR, s.f.).

Con esta frase, junto con imágenes sobre el mar, un velero solitario y varios turistas tomándose fotografías en "La Mano"7 o en el icónico Museo y Hotel Casa Pueblo, se inicia el audiovisual "Fin de semana en Punta del Este" (MINTUR , s.f.b.). Los turistas aparecen en todas las tomas: visitan lugares emblemáticos como la Glorieta del puerto, atraviesan el puente Leonel Viera hacia La Barra y disfrutan de las playas. También juegan en la piscina de un complejo habitacional, pero sobre todo practican deportes: caminan por el Arborettum Lussich (192 ha. de reserva forestal artificial), hacen surf, bucean en la Isla de Lobos (mayor reserva natural de lobos marinos de Sudamérica), navegan y practican beach polo. El audiovisual culmina con imágenes sobre las discotecas nocturnas y los grandes y lujosos edificios de la costa.

El audiovisual "Fin de semana en Punta del Este" producido por el MINTUR con un claro objetivo de promoción turística de la ciudad, continúa asociando a Punta del Este al ocio y la diversión, al igual que se hizo desde el relato fundante iniciado a fines del siglo XIX con los pioneros. La ciudad y el entorno natural que la rodea y la nutre (caracterizado por los árboles, la arena y el agua como elementos

\footnotetext{
7 "La Mano" o "Los Dedos" es una escultura ubicada en la playa de la Parada 1, realizada en 1982, por el artista chileno Mario Irrazábal quien llegó invitado por la Intendencia de Maldonado para participar del Primer Encuentro Internacional de Escultura Moderna al Aire Libre de Punta del Este.
} 
destacados (Da Cunha et al., 2012) está dispuesta y propuesta para ser consumida/disfrutada por los visitantes. Desde sus inicios, con la plantación de bosques para dominar a los grandes médanos móviles, los espacios han sido modificados, intervenidos y acondicionados. La construcción de calles y avenidas, de lujosas residencias y grandes edificios de apartamento, la instalación de hoteles, restaurantes y discotecas, así como la habilitación de espacios para pasear y practicar deportes ha ido reforzando la imagen del entorno urbano como un espacio al servicio del veraneante, ligado al ocio, la diversión, el hedonismo y el consumo de bienes naturales. Asimismo, el lujo, el glamour y la exclusividad han sido elementos importantes a la hora de construir un relato que año a año se refuerza desde los organismos estatales, los agentes inmobiliarios, los inversionistas, los medios de comunicación, entre otros.

Donde el lujo y la naturaleza convergen, Punta del Este es reconocido internacionalmente como uno de los principales balnearios de América y el más exclusivo de la región. Lujosas residencias de veraneo, altos edificios de apartamento frente al mar, enormes yates en el puerto, hoteles y restaurantes de lujo lo transforman en el balneario de mayor glamour de América (...) La ciudad balnearia es elegida para la realización de grandes fiestas de lujo, desfiles de moda de marcas de prestigio y una amplia gama de propuestas culturales de gran dimensión como el Festival Internacional de Jazz, el Festival Internacional de Cine o exposiciones de artistas contemporáneos de renombre [...] No en vano, fue elegida como destino de veraneo por grandes celebridades como el diseñador Ralph Lauren, el jugador del fútbol Zinedine Zidane, el cantante de Metallica James Hetfield o la colombiana Shakira. (MINTUR, s.f.)

Por otra parte, debido a los cambios acontecidos en las últimas décadas, dichas "persistencias representacionales" (Segura, 2009) asociadas a una ciudad lujosa y exclusiva han dado paso a la emergencia de otras representaciones que contribuyen a significar la ciudad como un lugar no tan exclusivo y al cual pueden tener acceso también otros sectores socioeconómicos. Las modificaciones en el espacio urbano y la práctica de los veraneantes-atribuida principalmente, como señalan Campodónico y Da Cunha (2009), a las modificaciones en el paisaje y la arquitectura con la construcción de altos edificios, la ampliación de la oferta de la vida nocturna, la remodelación del puerto, la mejoría en las instalaciones hoteleras y la mayor oferta gastronómica y de casinos-han propiciado la construcción de otros relatos, dejando en evidencia la relación dialéctica entre el discurso, las representaciones y sus efectos de realidad plasmados en las prácticas de los sujetos.

La ciudad de Punta del Este, a diferencia de lo que ocurría a inicios del siglo $\mathrm{XX}$, también puede ser visitada y disfrutada por personas ya no pertenecientes exclusivamente a las elites. Las imágenes que aparecen en el audiovisual sobre los complejos vacacionales, el disfrute de la playa y de otros espacios de acceso libre, así como la práctica de deportes masivos, confirman y dan sentido a este relato que establece y legitima un orden social a la vez que impone límites claros. En este 
sentido, podemos observar que el espacio habilitado para ser visitado por la clase media termina donde comienza la exclusividad. El visitante al cual va dirigido dicho spot publicitario no está convocado a adquirir lujosas residencias o chacras de veraneo, ni siquiera a alojarse en los altos edificios de apartamentos frente al mar o compartir los exclusivos restaurantes que frecuentan los sectores más privilegiados. En lugar de ello, se convoca al turista a disfrutar de todo aquello que es de libre acceso: las playas, una caminata por el parque Lussich, un recorrido guiado en un museo o a la contemplación de la calma del Puerto de yates.

A partir del análisis de dicho relato se puede identificar, por un lado, como se conjugan las representaciones sobre la ciudad más perdurables (como un espacio exclusivo y glamoroso reservado a una elite) y aquellas representaciones que dan cuenta de los cambios en la estructura del espacio urbano y las prácticas sociales producidas a lo largo del tiempo. Por otro lado, su análisis permite visualizar cuál es el orden social y espacial deseado y legitimado actualmente y a la vez cuáles son los límites establecidos para quien habita y/o visita la ciudad balnearia. Esto permite a su vez comprender, como afirma Rubio (2020) "...los límites expandidos de las ciudades, hasta dónde llegan en su extensión tangible e imaginaria, cómo se desbordan en temporalidad y en espacialidad " (p. 15).

Por otro lado (y en contraste), el audiovisual realizado por la joven productora Lucía Nieto Salazar, "Cuando nadie nos visita" (Nieto, 2018) inicia con tomas aéreas sobre los edificios de la península de Punta del Este en la noche. Las inmensas construcciones de cemento están a oscuras, nadie las habita. Apenas algunas luces encendidas dan a entender que son muy pocas las personas que residen en el lugar. Las siguientes tomas sobre las plazas, las calles y el puerto, refuerzan el primer mensaje sobre la soledad de los espacios. En las siguientes imágenes en las cuales aparece el océano, la Isla de Lobos y su faro, entran en escena los lobos marinos que duermen apacibles en las rocas. Cuando amanece, las tomas aéreas enfocan el contorno de la Isla y los lobos despabilándose y zambulléndose en el mar, y las gaviotas sobrevuelan el territorio. La cámara se aleja y las siguientes imágenes serán de los humedales del arroyo Maldonado y su rica biodiversidad. Posteriormente se vuelve al océano donde puede verse una enorme ballena Franca Austral y su cría nadando en el mar. La ciudad de Punta del Este y la Isla Gorriti aparecen detrás, en un segundo plano.

El relato en sus inicios podría entenderse como una denuncia o un reclamo asociado al declinar de una ciudad turística cuando finaliza la temporada y en consecuencia, se terminan los trabajos zafrales, se abandonan las grandes construcciones, concluyen la mayoría de las actividades recreativas, culturales, artísticas y deportivas. Pero a medida que transcurre el audiovisual, vamos comprendiendo que lo que parece haber sido un reclamo se transforma en una celebración. Lo que se celebra es la ausencia y los efectos antropogénicos privilegiándose la imagen de un entorno urbano mucho más sensible a la agencia del mundo no humano: las islas, el mar, las rocas, el humedal, los cerros, la fauna y la flora de cada ambiente.

El relato, así como las representaciones de la ciudad producidas en este corto audiovisual, constituyen el reverso del corto audiovisual "Fin de semana en 
Punta del Este" realizado por el MINTUR: en lugar de representar a la ciudad vinculada exclusivamente al turismo, el ocio, los deportes, el consumo de bienes naturales, el lujo y la exclusividad, problematiza los aspectos estructurales de la relación de las personas con su ambiente, invitando a abandonar una visión antropocéntrica y a explorar-quizás desde un enfoque posthumanista-el papel que juegan los seres no humanos en la construcción de los escenarios:

Me gustaría vivir en una canción, pero vivo aquí, en este lugar. Esta es la ciudad de Punta del Este, me gusta mucho por su naturaleza y además porque es un lugar solitario. Sus casas están deshabitadas, las utilizan los turistas en verano. Tantas casas vacías y tanta gente sin casa. Aunque a veces me pregunto si no habrá alguien observándome desde adentro. Una vez descubrí un secreto, hay personas que viven en los pestillos de las puertas. Así que esta parte de la ciudad está habitada dos meses al año más o menos. El resto del tiempo solo el viento recorre sus calles (Nieto, 2012).

Pensar en las casas deshabitadas, las personas que viven en los pestillos, el viento, la soledad nos convoca a descentrar el papel de lo humano en la representación del espacio urbano. Esto implica a la vez ampliar la asignación de grados variables de agencia y subjetividad a lo no humano y superar la dualidad naturaleza-cultura. Asimismo, invita a visualizar la multiplicidad del mundo, para pensar como afirman Durand y Sundberg (2019) sobre nuestros encuentros con lo no humano, sobre las relaciones y sobre lo que significa ser humanos en un mundo de seres y entes interdependientes e íntimamente interconectados.

En lo que respecta a las novelas Los trabajos del amor (2015) de Damián González Bertolino y Mal don (1973) de Silvina Bullrich, el propósito planteado consiste en buscar pistas sobre imágenes y representaciones de la ciudad-de su entorno y de la vida de sus habitantes y visitantes-que generalmente son invisibilizadas por otras producciones discursivas. En este sentido, pienso que tanto Los trabajos del amor como Mal don cuentan con la capacidad de enunciar algunos aspectos de las ciudades de Punta del Este y Maldonado que en el proceso de construcción y lucha por la consolidación y permanencia de determinadas formas de nombrar, significar y recordar las diferentes configuraciones del espacio urbano, son silenciados (Lacarrieu, 2007). Al citar algunos párrafos de las novelas seleccionadas, busco develar, como mencionan Silva y Gravano (2017), las diversas ciudades que conforman el espacio urbano y no solo las que demarcan las topografías de los planificadores y urbanizadores, la prensa o los libros de historia. De esta manera considero que se logra enriquecer las variantes de la complejidad urbana que la perspectiva reduccionista de otros discursos omite.

En el caso de Los trabajos del amor (2015), se trata del periplo de dos delincuentes (el Toto y Morales) que transitan por diferentes lugares de la ciudad de Punta del Este, la ciudad de Maldonado y sus alrededores. Con el objetivo de realizar un encargo de su jefe asociado a un muerto que llevan en la valija del auto, recorren durante un día y una noche de verano diversas zonas, cruzándose con policías, trabajadores de la construcción, prostitutas, matones, porteros y turistas. 
Las situaciones y los lugares que se presentan en ese periplo iluminan aspectos del espacio urbano completamente invisibilizados en otros discursos que buscan promoverla como un lugar asociado al disfrute de la urbe, de su entorno natural, del descanso, el lujo y la exclusividad. Asimismo, considero que el relato que se construye en la novela Los trabajos del amor sirve para comprender que las ciudades no pueden concebirse únicamente como el producto de un plan urbanístico "emocionalmente neutro" (Rubio, 2020), sino que deben poder pensarse como afirma Remedi (s.f), como una entidad múltiple con componentes físicos, territoriales, sociopolíticos, psicológicos, simbólicos discursivos, sensuales y estéticos. Asimismo, pone de manifiesto que una ciudad puede ser explorada y relatada en varias direcciones, encontrando cada vez nuevos significados, formas de organización de los espacios, modos de relacionarnos como sociedad urbana, símbolos, proyectos colectivos y personales, deseos y temores. En este sentido, a partir de la lectura de la novela de González Bertolino, podemos conocer algunas representaciones construidas en torno a la desigualdad económica, social, simbólica y territorial existente en las dos ciudades la cual queda plasmada en el encuentro con el turista, en la descripción de los barrios, en el tipo de viviendas, en los gustos y elecciones de los personajes (la decoración de sus casas, la vestimenta, los autos), los recorridos urbanos, las prácticas sociales en general:

En un barrio como aquel ni siquiera la madrugada podía ser apacible. Siempre había automóviles o motos con sus caños de escape destrozados o retocados, lo mismo daba, bramando y soltando humo por toda la cuadra; gente que andaba camino de un almacén; mujeres con su ropa interior bien acanalada entre las nalgas, sonriéndole, quizás; niños jugando a la pelota: tipos de su edad amontonados en una esquina, tomando cerveza y recontando monedas. "No hay cumbia" pensó. Siempre había alguien que encendía su equipo de audio y sacaba los parlantes por la ventana (González Bertolino, 2015, p. 91).

Del otro lado de la calle comenzaban los predios extensos del club de golf. El oscuro club house, como un templo pagano en la elevación de aquella zona, era el centro de un conjunto de residencias que de vez en cuando recibían a través de sus ventanales algunos pelotazos... Pero todos en paz. Una pelota perdida, un vidrio roto, un coche abollado podían marcar el inicio de una relación, una invitación a tomar el té o una disculpa elegante y una tarjeta asomando por una billetera. A cincuenta metros, en Kennedy, los vidrios se podían romper por pedradas o pelotas de fútbol. Y eso siempre significaba griteríos insultos o incluso golpes de puño (González Bertolino, 2015, p. 36-37).

Con las escasas visitas que había realizado a casa de don Gallet en compañía del Toto, y a diferencia de alguna aislada incursión presurosa por ambientes de ese tipo, Morales se había vuelto más atento y podía reconocer con cierto gusto los detalles de la decoración en los espacios íntimos de las personas que tenían dinero de verdad. 0 por lo menos esos detalles lo dejaban en un estado de confusión, o incluso de sorpresa, del que salía luego de un prolongado intento de asimilación, 
nunca plenamente logrado, pero no por ello carente de una cuota de excitación.

Así fue como vivió la entrada en aquel apartamento... La iluminación del corredor de entrada; la alfombra espesa y de figuras imposibles de acomodar con un ánimo simétrico; el cuadro en el que predominaba el color naranja a excepción de un par de líneas o trazos negros como raspones o mugre; el jarrón de barro cocido, a un lado, con sus cardos secos que serían como los de cualquier monte lleno de yuyos.... Morales se preguntaba por qué aquella gente elegía y pagaba lo que pagaba por aquellos objetos....

...Haber ingresado en su casa fue una revelación. Ya no era solamente dinero lo que anhelaba; sabía que lo necesitaba, pero no ignoraba que se trataba de un primer paso para acceder a lo que, por lo pronto, se le antojaba un misterio (González Bertolino, 2015, p. 229).

La desigualdad respecto a los bienes que se ostenta, los lugares que son frecuentados, así como el uso del tiempo, se hace más evidente a partir de la presencia del turista:

El Toto miraba hacia allí. Había gente que podía tomarse el tiempo de ir a esos lugares porque quería y porque podía, casi todos turistas gastando sus días y sus noches. Los observaba pasar con el sentimiento de querer manejar cualquiera de esos otros automóviles, incluso, por qué no, los que regresaban a la ciudad (González Bertolino, 2015, p. 39).

Se le ocurrió que los bocinazos se debían a que la gente estaba feliz al verlo proceder. Los turistas siempre se alegraban cuando veían que era detenido algún delincuente en los lugares que ellos frecuentaban (González Bertolino, 2015, p. 55).

Al igual que lo que sucede con Los trabajos del amor, la novela Mal don (1973) de Silvina Bullrich echa luz sobre algunos aspectos de la ciudad que son invisibilizados por aquellos discursos más potentes y dominantes a la hora de enunciar y significar Punta del Este como destino turístico.

En Mal don se puede conocer principalmente a través de las palabras del protagonista (un fernandino ${ }^{8}$ llamado Diego Bermúdez) algunas representaciones sobre la ciudad o las ciudades y su entorno natural, las transformaciones del espacio urbano sufridas a través de los años, la vida de los pobladores en verano y en invierno, así como su relación con el turismo:

Nací en un pueblo cuyo verdadero nombre enunciaré o callaré a lo largo de mi relato pero que por ahora se llamará Mal don pues a mi modo de ver el mazo le llegó mal barajado o Dios se distrajo mientras

\footnotetext{
${ }^{8}$ Así se llama a los habitantes de Maldonado debido a que el nombre oficial, desde sus comienzos, es San Fernando de Maldonado.
} 
nos agrupábamos (...). Lo cierto es que nuestra única función en el mundo parecía limitarse a atender durante tres meses a una horda de veraneantes y a pasar penurias durante el resto del año, un largo invierno silencioso que caía como un manto sobre nosotros después de noventa días de bulliciosas idas y venidas, de personas muy semejantes entre sí pero sin duda distintas aunque para mí sólo las diferenciaba el tono pálido verdoso de la piel que tenían los que llegaban y el tostado de los que se iban (Bullrich, 1973, p. 11).

Yo semiadormecido en el regazo de la abuela soñaba con ese mundo mágico de los Veraneantes, así con mayúscula, pues para mí no era una palabra que se refería a un estado transitorio, a una época del año caluroso, sino a una raza estable, a un título, algo como ser Príncipe o Rey. (Bullrich, 1973, p. 15)

Aquí también, su relato-atravesado por sentimientos de admiración y rencor con respecto a los veraneantes-deja en evidencia la situación de profunda desigualdad simbólica, social y económica que se instaura con la llegada de los turistas:

Para Diego, mamá y abuela y tía eran tres víctimas de los veraneantes. Yo sabía que no lo pasaban mal, las oía comentar con cierto interés las noticias de la radio y en cuanto pudimos tener la televisión, el año pasado pues antes no existía, la compraron y se divertían en grande; lo único que como a todas las mujeres de Mal don, las mortificaba hondamente era que las señoras de los veraneantes quisieran enseñarles a cocinar; las demás tareas de la casa las hacían mecánicamente desde la infancia, como quien camina o respira, pero obedecer a un libro de cocina era para ellas una especie de ofensa gratuita (Bullrich, 1973, p.141).

Diego veía mal al mundo porque vivía hundido en su rencor contra los veraneantes. Yo tampoco los quería: las chicas son más perversas que los varones y con la sonrisa más angelical del mundo preguntaban:

- ¿Cuando sea grande y el chalet sea mío lo vas a cuidar verdad?

- No sé -contestaba yo desorientada- ¿Por qué me decís eso?

- Y si ahora lo cuida tu abuela podes cuidarlo vos después. 0 lavarnos las sábanas como tu mamá. En casa dicen que ustedes son irremplazables, que tu abuela es una perla (Bullrich, 1973, p.130).

Al parecer, el relacionamiento con los turistas no solo instaura la violencia simbólica sino que propicia situaciones como la prostitución, visualizada por los habitantes locales como una de las pocas vías de ascenso social:

El perro era yo y aullaba a mi propia muerte, a mi terror de no poder salir nunca de Mal don. Sería jardinero, ayudaría a servir los asados de los veraneantes o entraría en la policía (...) Nunca viviría en una gran ciudad, en un piso alto, no conocería ni París, ni Nueva York, la 
torre Eiffel y el Empire State Building tan a menudo aparecidos en la pantalla. Y cuando mi chico fuera a jugar con los chicos de los veraneantes estos dirían: - No es nadie, es el chico del jardinero. (Bullrich, 1973, p.37)

Por otro lado, el relato de la ciudad en invierno destaca aspectos que denotan el sentir y el habitar de un lugar que queda atrás cuando el turismo desaparece. La ciudad es percibida desde el frío, la soledad de los chalets vacíos y la violencia material y simbólica que se impone a través de la desigualdad social establecida entre los veraneantes y los habitantes locales:

No obstante, me irritaba ver en medio de los jardines esas casas desocupadas que se alzaban como fantasmas de una época perimida, casas con sábanas, colchas y frazadas hasta con latas de conservas y whisky escocés dejados para ser saboreados en la próxima temporada. (Bullrich, 1973, p.19)

Pero a su vez, la ciudad será rememorada con nostalgia una vez que el protagonista la abandona para irse a vivir a Argentina. Los aspectos destacados desde la añoranza tienen que ver con la belleza del entorno natural, caracterizado por la costa y los montes de pinos y eucaliptus, con la frescura que otorga el mar en verano (en comparación al calor de Buenos Aires): "Sin embargo nunca pude soportar el calor de Buenos Aires quizás por haber nacido y haberme criado en un pueblo rodeado de bosques y de mar" (Bullrich, 1973, p.174); "Yo tenía lo que mis compañeros ricos no lograban: la posibilidad de pasar cuatro meses o los que me diera la gana en un pueblo cerca del mar con casas bajas, umbrosas y frescas." (p.174).

\section{Recapitulando}

El objetivo de este artículo consistió en trabajar con diferentes construcciones discursivas provenientes de la promoción turística, del arte y de la literatura $y$, a partir de ellas, identificar y caracterizar alguna de las representaciones existentes sobre la ciudad balnearia de Punta del Este, especialmente aquellas que refieren al espacio urbano, el entorno natural y las relaciones humanas entabladas entre los habitantes, los turistas y el territorio.

Para desarrollar dicha propuesta partí de la idea de que una ciudad no sólo está constituida por una realidad física, territorial y sociopolítica, sino que también es una construcción simbólica discursiva, producto de nuestra imaginación y del lenguaje. En este sentido, me interesó conocer los relatos y las representaciones construidas sobre la misma: aquellos que se imponen con fuerza y la enuncian desde organismos oficiales, literatura promocional, medios de comunicación, etc. y aquellos que quedan más al margen en los procesos de enunciación.

Considero que trabajar con estos relatos "alternos" o "marginales" contribuye a comprender las ciudades que conforman el espacio urbano y de esta manera, poder enriquecer las variantes de la complejidad urbana que las 
perspectivas reduccionistas de otros discursos omiten.

A partir del análisis del relato construido por el spot publicitario "Fin de semana en Punta del Este" considero que la ciudad es representada como un espacio intervenido y planificado al servicio del veraneante y el inversor. Asimismo, el entorno natural aparece representado como un bien de consumo dispuesto para ser utilizado y acondicionado según las necesidades imperantes. A través de las imágenes seleccionadas, vemos como el destino turístico se asocia al ocio, el disfrute, el lujo, el glamour y la exclusividad. Dichos elementos aparecen ya en el relato fundante de la ciudad balnearia y continúan siendo clave a la hora de significarla, y se refuerzan año a año desde la promoción turística, la publicidad, los agentes inmobiliarios, los inversores y también como vemos, desde un organismo oficial como el Ministerio de Turismo.

Asimismo, las "persistencias representaciones" son conjugadas con aquellas otras que evidencian los cambios ocurridos en la estructura urbana y las prácticas sociales, desde que el destino turístico dejó de pertenecer exclusivamente a la elite. Es así que a través de las imágenes y la voz en off, podemos comprender en apenas un minuto y doce segundos de duración, cuáles son los límites trazados así como cuál es el orden territorial urbano y social deseado y legitimado por este relato oficial para la ciudad de Punta del Este.

En el otro extremo, la producción audiovisual artística "Cuando nadie nos visita" nos convoca a problematizar el relato fundante y persistente que cuenta a Punta del Este desde una visión antropocéntrica, donde el territorio y los recursos naturales se encuentran a disposición de las necesidades reinantes provenientes de los inversores, la especulación inmobiliaria, la promoción turística, los límites que perpetúan la exclusividad. Este relato, a través de la imposición de imágenes mucho más sensibles a la agencia del mundo no humano-representado por las islas, el mar, las rocas, el humedal, los cerros, la fauna y la flora de cada ambiente-nos invita a abandonar la visión antropocéntrica y a explorar el papel que jugamos los seres no humanos en la construcción de los escenarios y así superar la dualidad naturaleza-cultura, permitiéndonos visualizar la posibilidad de construir otras relaciones con el mundo y lo que significa ser humanos en un mundo de seres y entes interdependientes e íntimamente interconectados.

Por último, pienso que los relatos de las dos obras literarias Los trabajos del amor y Mal don contribuyen a visualizar otros aspectos de la ciudad-de su entorno y de la vida de sus habitantes y visitantes-que generalmente son invisibilizados por otras producciones discursivas. Con la transcripción de algunos párrafos de ambas novelas, busqué iluminar las "otras ciudades" que conforman el continuo urbano Maldonado-Punta del Este y de esta manera, contribuir a enriquecer las variantes de la complejidad urbana que la perspectiva reduccionista y homogénea de otros discursos omite.

En ambas novelas se enuncia fuertemente la desigualdad socioeconómica existente en las dos ciudades. Esta se ve plasmada explícitamente en la descripción de los barrios, de las viviendas y los vehículos que transitan el territorio y de forma más sutil en la caracterización de los gustos, hábitos y uso del tiempo de los 
diferentes grupos sociales. Dicha desigualdad se hace más evidente con la llegada del turismo. Los veraneantes son representados por los locales a partir de sentimientos contradictorios de admiración, rechazo y envidia. Particularmente en Mal don, podemos notar que estos sentimientos no exentos de contradicción y ambigüedad también atraviesan y producen las representaciones sobre la ciudad con el cambio de temporada, cuando el turismo que tanto perturbó a la vida de los pobladores locales desaparece. En invierno la ciudad es percibida desde el frío, la soledad de los chalets vacíos y la violencia simbólica que se impone con las mansiones deshabitadas y el abandono por parte de los turistas, de una ciudad balnearia por mejores destinos. Pero a su vez, es interesante rescatar las representaciones que valoran esa misma ciudad, la cual en el caso de Mal don será rememorada con nostalgia una vez que el protagonista la abandona para irse a vivir a Argentina. Los aspectos destacados desde la añoranza tienen que ver con la belleza del entorno natural, con la frescura que otorga el mar en verano (en comparación al calor de Buenos Aires) así como con la honestidad y la perseverancia laboral de sus habitantes.

En la ciudad narrada en la obra de Silvina Bullrich y Damián González Bertolino, así como en el audiovisual producido por Lucía Nieto Salazar, aparecen aspectos que a pesar de no ser enunciados desde el discurso dominante [o quizás precisamente porque no lo son], intervienen en los procesos simbólicos de significación y apropiación del espacio y la memoria urbana y por tal motivo, deben ser considerados si queremos entender la ciudad en toda su complejidad y extensión en los estudios académicos, en los debates públicos y principalmente a la hora de planificar su promoción turística, su ordenamiento y desarrollo.

\section{Referencias}

Bullrich, S. (1973). Mal Don, Buenos Aires, Argentina: Ed Emecé.

Da Cunha, N., Campodónico, R., Maronna, M., Duffau, N. y Buere, G. (2012). Visite Uruguay. Del balneario al país turístico 1930 - 1955. Montevideo, Uruguay: Ediciones de la Banda Oriental.

Diario La Nación (30 de junio de 2020). Aumentó número de consultas de argentinos que analizan venir a Uruguay. ¿Qué ven en el país? Diario La Nación. Recuperado de https://negocios.elpais.com.uy/noticias/historias-siete-empresarios-argent inos-decidieron-vivir-uruguay.html

Durand, L. y Sundberg, J. (2019). Sobre la ecología política posthumanista. Revista Sociedad y Ambiente7(20), pp. 7-27. doi: 10.31840/sya.v0i20.1989.

González Bertolino, D. (2015). Los trabajos del amor. Montevideo, Uruguay: Ed. Estuario. 
Green, R. (2008.) Imaginando la ciudad: Revisitando algunos conceptos claves. Revista Bifurcaciones, (7). Recuperado de : http://www.bifurcaciones.cl/007/Editorial.htm

Instituto Nacional de Estadística (2011). Resultados censo 2011. población, crecimiento y estructura por sexo y edadRecuperado de : . http://www.ine.gub.uy/documents/10181/35289/analisispais.pdf/cc0282 ef-2011-4ed8-a3ff-32372d31e690

Lacarrieu, M. (2007). La insoportable levedad de lo urbano. EURE, XXXIII (99)), pp. 47-64. Santiago de Chile. Recuperado de : https://www.eure.cl/index.php/eure/article/view/1359/452

Lindón, A. (2007). Diálogo con Néstor García Canclini ¿Qué son los imaginarios y cómo actúan en la ciudad? EURE, XXXIII (99), pp. 89-99. Pontificia Universidad Católica de Chile. Santiago, Chile. Recuperado de : http://www.redalyc.org/articulo.oa?id=19609908

Nieto Salazar, L., Cuinat, M. (Productores) y Nieto Salazar, L. (Directora). (2018). Cuando nadie nos visita. [Cinta cinematográfica] Uruguay:Blacfox Producciones. Disponible en: https://vimeo.com/286233971

Nieto Salazar, L. (Productor). (2012). Las calles de mi ciudad. [Cinta cinematográfica] Uruguay:Blackfox Producciones. Disponible en: https://www.retinalatina.org/video/las-calles-de-mi-ciudad/.

MINTUR (2019). Datos oficiales en:

https://www.gub.uy/ministerio-turismo/comunicacion/noticias/2019-ingr esaron-uruguay-3220602-turistas-us-1753-millones-divisas (consultado agosto 2020)

Ministerio de Turismo (s.f.a)Web oficial https://turismo.gub.uy/index.php/lugares-para-ir/region-este/ciudades/p unta-del-este

Ministerio de Turismo (s.f.b). Fin de semana en Punta del Este [Corto audiovisual]. Uruguay: Uruguay Natural.

Jodelet, D. (1986). La representación social: fenómenos, concepto y teoría. Representaciones sociales: un área en expansión (s.d). Recuperado de: https://www.researchgate.net/publication/327013694_La_representacion social fenomenos concepto_y teoria

Jodelet, D. (1991). Representaciones sociales: un área en expansión En: J. Páez(Ed.), Sida: imagen y prevención. Madrid, España: Ed. Fundamentos.

Lindón, A. (2007). Diálogo con Néstor García Canclini ¿Qué son los imaginarios y 
cómo actúan en la ciudad? EURE, XXXIII(99), pp. 89-99 . Pontificia Universidad Católica de Chile, Santiago, Chile. Recuperado de: http://www.redalyc.org/articulo.oa?id=19609908

Solomita, M. (21 de junio de 2020). Alquileres baratos, búsqueda de trabajo o vida de lujo: todos quieren ir a Maldonado y comuna lidia con carencias de sus servicios. Diario El País. Recuperado de: https://www.elpais.com.uy/que-pasa/alquileres-baratos-busqueda-vida-luj o-todos-quieren-maldonado-comuna-lidia-carencias-servicios.html

Remedi, G. (s.f.) Representaciones de la ciudad: apuntes para una crítica cultural. [Publicación en blog] Recuperado de: http://www.henciclopedia.org.uy/autores/Remedi/Ciudad1.htm

Rubio, H. (2020). Narrar la arquitectura y la ciudad: Tendencias teóricas y metodológicas, en la segunda mitad del siglo XX. Revista Contexto, XIV(20) Recuperado de: https://dialnet.unirioja.es/servlet/articulo?codigo=7433576

Segura, R. (2009). La persistencia de la forma (y sus omisiones). Un estudio del espacio urbano de La Plata a través de sus ciudades análogas. Cuadernos de Antropología Social,(30), pp. 173-197. Recuperado de: http://revistascientificas.filo.uba.ar/index.php/CAS/article/view/2783

Silva, A. y Gravano, A. (2017). Ciudades (medias) y comunicación: cruces, nudos y aperturas. Inmediaciones de la comunicación,12(1), pp.39-65. Recuperado de:

https://revistas.ort.edu.uy/inmediaciones-de-la-comunicacion/article/vie $\underline{\mathrm{w} / 2665}$

Trochón, I. (2017). Punta del Este: El Edén Oriental. Montevideo, Uruguay: Fin de Siglo.

Varese, J. (2019). De náufrago a pionero. Montevideo, Uruguay: Planeta.

Vera, P., Gravano, A. y Aliaga, F. (Ed. académicos) (2019). Ciudades indescifrables: imaginarios y representaciones sociales de lo urbano. Colombia: UNICEN. 